Revista Iberoamericana, Vol. LXXX, Núm. 247, Abril-Junio 2014, 653-675

\title{
VERLO. LEERLO. EDUARDO LALO FRENTE A LA ESCRITURA FOTOGRÁFICA LATINOAMERICANA
}

\author{
POR \\ LOURDES DÁvILA \\ Universidad de Nueva York
}

\begin{abstract}
El siglo 20 fue el tiempo de la imagen. El peligro de que el artificio y el contenido no encontraran un balance, $y$ la lectura (y la escritura) acabaran en un callejón sin salida, era un riesgo que se debía tomar.

Cancel, Literatura y narrativa puertorriqueña: la escritura entre siglos

Las imágenes no son ni verdaderas ni falsas, algo cuya relación con un real, que posibilitaría un criterio de verdad, ha desaparecido [...] De manera efectiva, lo real en cuanto presencia "natural" u originaria se desvanece en la absoluta visibilidad de la simulación. $Y$ lo que debe hacer el arte, utilizando también imágenes, es, a diferencia del simulacro, conservar el rastro de esta desaparición, atisbar los indicios homicidas dejados tras el asesinato. A diferencia de las imágenes mediáticas, el arte asume la desaparición.

Luis Sánchez González, “Jean Baudrillard: Simulacro, seducción, ilusión, fotografía”
\end{abstract}

Pensemos, como premisa, que el saber fotográfico es un posible espacio desde donde ver, leer, la evolución del pensamiento latinoamericano y sus discursos a comienzos del siglo veintiuno. Pensemos también, como premisa básica, que la fotografía es un dispositivo que se asienta entre la historia y la literatura, sirve de gozne para un pasaje continuo entre ambas, y su forma y manipulación puede darnos claves específicas sobre la relación de la literatura con la historia. Veamos y leamos así el comienzo de la obra de Eduardo Lalo, donde (2005): un edificio multipiso vacío y abandonado, en proceso de convertirse en ruinas; los ojos en un cartel cubiertos con la violencia de una mancha oscura que sin embargo no logra cubrir la potencia de la mirada; las patas de metal de una mesa sin superficie sobre una superficie de cemento llena de grietas, 
frente a una pared marcada; un cuarto dilapidado con un colchón en el suelo a cuyos pies descansa un teléfono; un auto dentro del cual los pasajeros esperan un cambio de señal; un puerto inaccesible tras un alambrado; una cruz en un cementerio que marca un espacio sin lápida y sin primer nombre, sólo con la familiaridad de un apellido; un motociclista en movimiento cuyo punto de mira no es visible. Nombramos las fotos en el libro desde la acumulación de una serie indeterminada de nombres comunes y artículos indefinidos, que vuelven a aparecer al final del libro como sustantivos, en una lista. Tenemos, por supuesto, la huella imborrable que con el tiempo se vuelve más difícil de perseguir, índices que se van borrando y disolviendo en el tiempo, con el tiempo. Dos ejemplos: el edificio está en Santurce, Puerto Rico, en la parada 8. El cuarto es el cuarto de la antigua casa del escritor. Sin embargo, en ausencia del "marco histórico real”, construimos un relato con las marcas de la historia: en conjunto, las fotos podrían ser la narración apocalíptica de la vida urbana y la tecnología, la presencia indeleble de un estado-ley que determina una serie de límites, el anuncio del final del progreso humano y la historia observados en la acumulación de sus residuos. Podemos leer las fotos desde esa construcción, que articula una serie de relaciones con los discursos del saber, o podemos ver cómo cada foto se refiere individualmente a otras narraciones artísticas que a su vez nos devolverían a esa narración apocalíptica inicial. Así, las fotos significan desde su reiteración como imágenes en un plano estético elaborado a base de su referencialidad. Por ejemplo, la foto del edificio residencial vacío adquiere particular fuerza con la referencia de la secuencia de la implosión de un complejo de residencias multipiso abandonado en la película Koyaanisqatsi (término hopi que significa "Vida fuera de orden”), de Goddfrey Reggio y Philip Glass (1975-1982). ${ }^{1}$ La foto del colchón sobre el piso en un cuarto dilapidado bien podría ser del cuarto de Larry John en Maldición eterna al que lea estas páginas, de Manuel Puig (1980). La foto del auto dentro del cual los pasajeros viven un estancamiento sin fin podría ser un primer plano en el relato "La autopista del sur” de Julio Cortázar (1966). Las fotos, al igual que las palabras, comunican y significan algo a través de un complejo de relaciones con sus referentes inmediatos, con hechos y acontecimientos históricos, con imágenes y discursos diversos y con su puesta en circulación. Las fotos hacen historia y literatura, comunican, duplican, producen los discursos. ${ }^{2}$

Eduardo Lalo es un escritor, artista visual y fotógrafo del siglo xxi. La escritura de tres de sus libros, Los pies de San Juan (2002), donde (2005), El deseo del lápiz. castigo,

1 Se trata del complejo Pruitt-Igoe, una serie de viviendas pagadas por gobierno de St. Louis y diseñadas por Minoru Yamasaki, el mismo arquitecto que diseñó las torres gemelas del World Trade Center. El complejo se habilitó en 1955 y su deterioro comenzó casi inmediatamente. La demolición comenzó en 1972, menos de veinte años después de su construcción.

2 Pienso aquí en el último texto publicado por W.T.J. Mitchell, Cloning Terror. The War of Images, 9/11 to the Present, donde W.T.J. Mitchell habla sobre la relación entre la fotografía, la historia, y el clon.

Revista Iberoamericana, Vol. LXXX, Núm. 247, Abril-Junio 2014, 653-675
ISSN 2154-4794 (Electrónico) 
urbanismo, escritura (2010), es fotográfica y textual. De estos tres textos, elijo hablar mayormente de donde, por la forma en la cual palabra e imagen ejemplifican mejor la relación entre la foto, la palabra y la historia.

\section{INTRODUCCIÓN NECESARIA}

Jacques Rancière, en The Future of the Image (2007), comienza su comentario sobre el discurso fotográfico dialogando con la teoría paradigmática de Roland Barthes. Aunque podría parecernos anacrónico, la teoría de Barthes sirve para articular un cuestionamiento que no se ha concluido aún en los debates sobre la fotografía y que, como veremos, resulta crucial para nuestro estudio. Barthes, como sabemos, formula dos estadios de lectura de la imagen fotográfica, para hacer hablar a la imagen desde su "silencio". Traza una relación directa entre la naturaleza indéxica de la imagen fotográfica (por la cual toda foto contiene una huella de su referente) y su poder de producir un efecto inmediato, un afecto, a través del punctum. Esto lo contrapone al studium, es decir, a la manera en la cual toda foto se convierte en material para ser codificado y explicado de acuerdo a diversos discursos (10). Ambos estadios conciben la imagen fotográfica como un habla que contiene su lengua:

Both conceive the image as speech which [sic] holds its tongue. The former made its silence speak; the latter makes this silence the abolition of all chatter. But both play on the same inter-convertibility between two potentialities of the image: the image as raw, material presence and the image as discourse encoding a history. (11)

Esta consagración de los dos silencios de la imagen fotográfica transferibles a una presencia material y a un código producido, es una respuesta particular al régimen de articulación entre lo visible y lo decible (de cualquier imagen, visual o textual) dentro del cual tuvo su origen la fotografía como arte. Es decir, no es la ciencia técnica fotográfica, sino la poética de la imagen, la que nombra el silencio de la foto y su potencialidad de habla:

Photography did not become an art because it employed a device opposing the imprints of bodies to their copy. It became one by exploiting a double poetics of the image, by making images, simultaneously or separately, two things: the legible testimony of a history written on faces or objects and pure blocs of visibility, impervious to any narrativization, any intersection of meaning. (11)

La fotografía asume esa poética de la imagen que hace que la imagen estética gravite constantemente entre un jeroglífico que puede ser leído y una presencia desnuda (14-15). Ese gravitar constante, la genealogía misma de la imagen estética, es lo que,

\footnotetext{
Revista Iberoamericana, Vol. LXXX, Núm. 247, Abril-Junio 2014, 653-675 ISSN 0034-9631 (Impreso) ISSN 2154-4794 (Electrónico)
} 
según Rancière, Barthes está dispuesto a eliminar para plantear un contraste inalterable y arbitrario entre el punctum y el studium, para proteger a la fotografía de la semiología de descodificación. Lo que Barthes pretende eliminar con el punctum es la "historia de las relaciones [...] entre las imágenes del arte, las formas sociales de la producción de imágenes, y los procedimientos teóricos de crítica de las imágenes” (15). Es decir, gestiona un quiebre permanente entre la fotografía y las imágenes, reserva un espacio cerrado y privilegiado para la presencia desnuda, indéxica, de la foto, más allá de su funcionamiento dentro de cualquier discurso, con un gesto especial en contra de la imagen estética.

Manejo aquí dos supuestos que han marcado el discurso de la fotografía y en los que Rancière se basa para efectuar su crítica, tomando a Barthes como ejemplo canónico. ${ }^{3}$ El primero afirma "el silencio" de la imagen visual en general, y los acercamientos o distancias que proponemos entre lo visible y lo decible que determinan las distintas etapas de historización de la imagen visual y su relación con el lenguaje verbal. El segundo se refiere a la particularidad de la producción material de la foto, su tecnología, su relación con su referente, que nos lleva a centrarnos en una interrupción privilegiada: interrupción del habla, interrupción de la escritura, interrupción del discurso, que determina también el privilegio de una presencia "desnuda" definida a través de su huella indéxica. Y aún después de los debates recientes producidos por el advenimiento de la fotografía digital (ver en especial los argumentos entre Rubén Gallo y Eduardo Cadava), estos supuestos, y su relación con la huella indéxica de la fotografía, se han mantenido como constantes.

Rancière revisa la teoría de Barthes enfocándose en la manera en que la escritura también puede verse, leerse, dentro de esos dos supuestos de silencio e interrupción, y no solamente desde su potencialidad particular de decir, de significar desde un habla específica. Es decir, el lenguaje verbal ha comprobado también desde siempre su materialidad, su capacidad de funcionar como interrupción, su capacidad de negar o contener el habla. Rancière acuña entonces un nuevo término para leer las producciones que combinan lo visible con lo decible: la oración-imagen.

I propose to call this term of measurement the sentence-image. By this I understand something different from the combination of a verbal sequence and a visual form. The power of the sentence-image can be expressed in sentences from a novel [...] or the relationship between the said and unsaid in a photograph. The sentence is not the sayable and the image is not the visible [...] The sentence function is still that of linking. But the sentence now links in as much as it gives flesh. [...] For its part, the

\footnotetext{
5 Rancière no es el único ni el primero en explicar esta postura de Barthes; véanse por ejemplo los ensayos editados por Jean-Michel Rabaté en Writing the Image alter Roland Barthes. Su escritura no se limita a explicar con claridad los problemas de la crítica bartheana y la forma en que sus postulados han formado postulados posteriores, sino que elabora un posible contra-discurso, otra posible manera de leer la foto y los textos que la utilizan.
}

Revista Iberoamericana, Vol. LXXX, Núm. 247, Abril-Junio 2014, 653-675
ISSN 2154-4794 (Electrónico) 
image has become the active, disruptive power of the leap, that of the change of regime between two sensory orders. The sentence-image is the union of these two functions. It is the unit that divides the chaotic force of the great parataxis into phrasal power of continuity and imaging power of rupture. (46)

Las producciones híbridas contemporáneas tendrían que leerse entonces no desde un espacio que distinga arbitrariamente la potencialidad de habla de la imagen y la palabra, sino las formas en las cuales estas combinaciones producen también combinaciones específicas entre lo visible y lo decible, entre la continuidad y la interrupción, que no provienen necesariamente y particularmente de lo visual y lo verbal.

Consciente o inadvertidamente, abierta o tácitamente, la teorización, la producción, la recepción y el análisis de las producciones que combinan fotografía y lenguaje verbal llevan la marca de los supuestos establecidos para la fotografía y la palabra. En el caso particular de Barthes, el sujeto que observa reserva el índice fotográfico y la presencia desnuda para asegurar la intimidad privada y del afecto más allá de cualquier discurso. Pero lo cierto es que el doble silencio de la foto, el índice fotográfico y el valor de la foto como "presencia desnuda" enfrentado a la codificación de los discursos, se inscriben en los discursos teóricos de la fotografía y en el discurso de las colaboraciones entre fotografía y texto. Como elementos de tensión confirman la figuración benjamiana, previa al discurso de Barthes, de una presencia muda en toda foto que busca un habla, que demanda una leyenda, una articulación verbal en "A Short History of Photography” (1931), o de la fotografía y su reproducción mecánica que pone en juego la autenticidad de la obra de arte en "The Work of Art in the Age of Mechanical Reproduction" (1936) o de la fotografía como representación de un momento fulminante de visión previo a su desaparición en "Theses on the Philosophy of History" (1939). Forman parte de la gramática de la foto y la tensión con lo real en el libro de Susan Sontag On Photography (1977) y en Regarding the Pain of Others (2004) que incluye, entre otros elementos, la producción de un lenguaje que es también un medio de ordenar, coleccionar, catalogar, dirigir, controlar los sujetos fotografiados que se vuelven inmediatamente objetos de estudio. Confirman la disputa palabra-imagen que resume W.J.T Mitchell en su obra Picture Theory (1994), la verbalización de lo que “desean” las imágenes en What do Pictures Want (2005) y la habilidad de duplicar y producir, reproducir clonar la historia y el terror en su libro más reciente Cloning Terror. The War of Images, 9/11 to the Present (2010). Más aún: forman parte de los discursos que tratan de la puesta en circulación de las imágenes en la sociedad. En una sociedad de consumo, el código mercantil y del espectáculo que determina las relaciones sociales domina sobre la presencia desnuda del referente (Guy Debord, La Societé du spectacle, 1967). Y Baudrillard nos dice que en una sociedad donde la realidad ha dado paso a la simulación, es posible trazar ese proceso por el cual el signo deja de referirse a una "realidad profunda" porque la realidad misma es simulación; de cierto modo Baudrillard nos dice entonces que no hay nada

\footnotetext{
Revista Iberoamericana, Vol. LXXX, Núm. 247, Abril-Junio 2014, 653-675 ISSN 0034-9631 (Impreso) ISSN 2154-4794 (Electrónico)
} 
más allá de los códigos (Simulacres et simulation, 1981). El señalamiento aquí no es que la referencia desnuda y la codificación son formas que dominan el discurso sobre la imagen fotográfica desde Barthes; referencialidad y codificación es el espacio donde texto e imagen se han debatido desde siempre, inclusive, como comprueba Rancière, antes del advenimiento de la tecnología fotográfica. Lo que se precisa aquí entonces, en primer lugar, es subrayar la manipulación del índice fotográfico por Barthes y el quiebre que esa manipulación implica en el discurso de la imagen, y, en segundo, observar cómo ese juego entre presencia desnuda y codificación, cómo la manipulación del índice fotográfico, puede utilizarse para diagnosticar el estado de los discursos en la escritura actual.

La influencia de estos supuestos, que hemos observado hasta aquí al nivel de la crítica, no es tan sólo visible en la escritura europea y norteamericana, sino que se hace ver particularmente en Latinoamérica. La compilación Photography and Writing in Latin America: Double Exposures (2006), es, como mismo señalan sus editoras, Marcy E. Schwartz y Mary Beth Tierney-Tello, un hito en la crítica en Latinoamérica, por ser el primer libro que documenta y comenta la colaboración extensa entre escritores y fotógrafos en Latinoamérica desde la Revolución Mexicana hasta finales del siglo veinte (1-2). Su gesto inicial es establecer su deuda a muchas de las críticas de Occidente mencionadas arriba: la introducción, de hecho, comienza con un epígrafe de Susan Sontag. No es de extrañarnos, entonces, que esta compilación crítica revele tácitamente los supuestos mencionados arriba como estructurantes de la colaboración latinoamericana entre fotografía y el texto. La introducción establece que

Whether for testimonial immediacy, historical memory, narrative, or poetic intertextuality, photographs encourage verbalization, according to the contributors here, whereby they motivate narratives, problematize their stories, and defy the visual conventions of portraiture, documentary, and journalism. (13)

La palabra encourages (anima, alienta), que aparece en cursiva en el original, reafirma la premisa del silencio de la fotografía: las fotografías animan, motivan, la producción verbal y el diálogo de la palabra con la imagen visual. Se considera entonces la escritura verbal como un hablar de, con, contra, ese silencio (y, en muchas ocasiones, la manipulación y el control que el Estado realiza sobre ese silencio). Por supuesto, la mayoría de las producciones híbridas son colaboraciones entre fotógrafos y escritores, y, en la mayoría de los casos, la fotografía precede al texto. El texto en gran parte se vuelve un comentario de la foto, un hacerla hablar desde los discursos e ideologías prevalecientes. En otro momento de la introducción, al citar la entrevista con Nelly Richard que aparece en la compilación, vemos cómo el índice fotográfico se juega a distintos niveles con los diversos códigos discursivos. Las escritoras señalan cómo la

\footnotetext{
Revista Iberoamericana, Vol. LXXX, Núm. 247, Abril-Junio 2014, 653-675 ISSN 0034-9631 (Impreso) ISSN 2154-4794 (Electrónico)
} 
fotografía en Latinoamérica comenzó como un recurso técnico que pronto se convirtió en una "figura teórica”, una "estrategia retórica e ideológica":

\begin{abstract}
Transformed into a medium with potent ideological capacities, photography projects the desire for otherness from abroad, captures the struggles of political independence and revolution, and records the progression toward cultural autonomy through both journalistic and artistic expression. Clearly photography has been manipulated as an instrument of the state while it has also served as a strategy of resistance. The use of photography in relation to the state and citizenship in Latin America falls into three general functional categories: recording ethnography, imposing surveillance, and documenting human rights abuses. (3)
\end{abstract}

Es decir, la fotografía como “certificado de presencia” (Tierny-Tiello 88), su valor indéxico (que Barthes utiliza para la producción del afecto del punctum), es utilizado por el imperio para nombrar al otro y apropiarse de él (ya sea en estudios etnográficos, de criminología, médicos o psicológicos), por el estado para controlar a los ciudadanos (las tarjetas de identificación) y por el arte para producir un lenguaje de resistencia y visibilidad a sujetos marginalizados. ${ }^{4}$ Ese "hacer visible" de la fotografía, en los momentos en los cuales se relaciona con el testimonio, el documento, la historia, coloca el índice fotográfico como supuesto necesario que sostiene, corrobora, cristaliza los códigos discursivos que "comenta".

No se debe entender esta lectura como una crítica negativa a una colección que, desde el comienzo de la introducción, encuadra el acercamiento textual en la celebración de "manifestations of words and images as they join forces in Latin America in ways that directly problematize the region's post-colonial, violent, and conflicted relationship with Europe and the United States" (1). Todo lo contrario: el acercamiento es a un mismo tiempo un diagnóstico, demuestra hasta qué punto la fotografía en los textos híbridos latinoamericanos se lee como resorte productor de sentido, desde un espacio "post-colonial”, “subalterno": la fotografía se hace y se lee como coagulación de los discursos de Occidente (historia, política, sociología, psicología), como cristalizaciones de la mirada Occidental, de los procesos de colonización y de la autoridad del estado y como posible forma de resistencia. Y lo hace, precisamente, señalando tanto la presencia desnuda del objeto fotografiado, la huella de su índice, como los discursos de codificación que circulan en torno al sentido de las imágenes, y que de cierta manera controlarán también el habla en los textos híbridos representados en la compilación crítica.

4 Ver en particular el texto de Mary Beth Tierny-Tiello de la colección, “On Making Images Speak: Writing and Photographs from Three Texts in Chile”, 87-116.

Revista Iberoamericana, Vol. LXXX, Núm. 247, Abril-Junio 2014, $653-675$
ISSN 0034-9631 (Impreso) 
El comentario crítico-textual de la fotografía lleva a los textos híbridos en Latinoamérica a una saturación de los discursos, ${ }^{5}$ saturación que irá en aumento en las producciones de finales de siglo veinte, ya que éstos intentan lograr la visibilidad y presencia de los sujetos latinoamericanos, a menudo marginados, de la historia, frente a ideologías y discursos que caminan al borde de su propio precipicio. Así, como ejemplos, he hablado antes sobre cómo Edgardo Rodríguez Juliá, en Puertorriqueños. Álbum de la sagrada familia puertorriqueña a partir de 1898 (1998), define al sujeto histórico puertorriqueño y elabora una densa teorización fotográfica entre el documento histórico y la memoria personal, a partir de la caída de la técnica fotográfica al ámbito popular en el traspaso del territorio puertorriqueño de España a Estados Unidos; cómo Diamela Eltit, en El infarto del alma (1994), otorga ciudadanía a los sujetos fotografiados por Paz Errázuriz en el hospital de Putaendo de Chile, no tan sólo en el estado civil de Chile, sino en la ciudad literaria de la cultura amorosa, desde el romanticismo tísico del siglo diecinueve hasta la sublimación surrealista de la locura en el siglo veinte; cómo Elena Poniatowska, en Las soldaderas (1999), utiliza la fotografía histórica para documentar la presencia y agencia de la mujer no tan sólo en la Revolución Mexicana, sino en el imaginario cultural de la literatura y el cine. Photography and Writing in Latin America presenta otros ejemplos, entre ellos: Las genealogías (1981) de la escritora mexicana Margo Glantz; La destrucción del reino (1992) y El mundo sin Xóchitl (2001) del escritor peruano Miguel Gutiérrez y el fotógrafo Julio Olavarría (11-13).

La saturación va llevando también progresivamente a la fragmentación del lenguaje verbal; es decir, los códigos discursivos van negando cada vez más una narración cohesiva, van conduciendo cada vez más al desgaste y a la erosión del lenguaje, van mostrando cada vez más su propio límite. La fotografía se señala en esta saturación como una manifestación del límite, provoca una escritura en ese límite. Mario Bellatin, por ejemplo, cuya escritura es marcadamente híbrida, y quien se distingue por ser uno de los mejores exponente actuales del medio, escribe con fotografía y texto, confirma y anula los discursos de la fotografía como prótesis interna y externa de sus relatos, se da de lleno al fragmento textual como exposición del límite de la escritura. Y, de hecho, si al principio efectuaba colaboraciones con fotógrafos (en especial con Ximena Berecochea), dos de sus últimas publicaciones (Los fantasmas del masajista, Biografía ilustrada de

5 La saturación se produce en parte como resultado de una particularidad de estos textos, que los diferencian de las producciones híbridas europeas o norteamericanas (piénsese por ejemplo en la obra completa de Sebald o en la obra de Jonathan Foer Extremely Loud and Incredibly Close, de 2005, sobre los eventos del 9/11). Nos dice la colección crítica que mencionamos anteriormente que gran parte de la producción de narrativas híbridas latinoamericanas contiene como elemento principal una puesta en escena explícita de la teoría fotográfica (15). Así, nuestro supuesto entonces es que leer estos textos es también leer cómo la fotografía puede manipularse como elemento discursivo, como elemento de respuesta, resistencia a, o comentario sobre, los discursos de Occidente.

\footnotetext{
Revista Iberoamericana, Vol. LXXX, Núm. 247, Abril-Junio 2014, 653-675 ISSN 0034-9631 (Impreso) ISSN 2154-4794 (Electrónico)
} 
Mishima, ambos de 2009), llevan la marca de su propia escritura fotográfica. Pero quizá la representación del límite de los discursos de los cuales hemos venido hablando hasta ahora no lo muestra un texto híbrido, sino la novela de Roberto Bolaño, Estrella distante (1996), la que, aunque no contiene imágenes fotográficas reales, contiene quizá una de las mejores representaciones de las implicaciones de los límites discursivos de la representación fotográfica en la escritura latinoamericana. En esta novela, el personaje de Carlos Wieder organiza una exposición fotográfica en una habitación privada de la casa de un amigo, que puede leerse como la máxima poetización del mal, el mal que se representa a sí mismo, que habla por sí mismo. Y lo hace, precisamente, llevando la fotografía a su límite. El límite de la referencialidad máxima, de la mayor huella indéxica: las fotografías capturan el horror de la historia real, el momento de tortura de los sujetos previo a la muerte, el instante mismo donde se actualiza la transformación del sujeto en objeto. El límite de la poetización: se representa la muerte, el horror, el mal, como la forma más sublime del arte, en un habla después de la cual sólo resta el silencio. Desde esa escena podemos leer el horror de uno de los límites de los discursos de la fotografía.

\section{DESDE DONDE UNA SERIE DE SIGNOS...}

La obra híbrida de Eduardo Lalo es una respuesta particular a esa saturación de los discursos, producida desde un ámbito que conoce como "privilegiado": el espacio actualmente inconcebible de no poder ser "poscolonial" (de hecho, es una palabra que parece evitar a propósito). Su escritura contiene la marca de un evento de pérdida original y originario, no concluido, cuyo producto es una serie de pérdidas "invisibles". ${ }^{6}$ La visión del triunfo y el fracaso de las ideologías posteriores a la independencia de las naciones latinoamericanas, la revisión de los discursos ideológicos de Occidente realizados a partir del fin de las dictaduras latinoamericanas desde un espacio-nación, no son pertinentes para este escritor que trabaja desde esa pérdida. Su escritura, por

6 Utilizo a aquí el término "pérdida" siguiendo mi lectura del libro de Adi Ophir, The Order of Evils. Toward an Ontology of Morals (2005), que de cierta manera iluminará toda la continuación de este trabajo. "Loss is a singular type of disappearance: the irreversible disappearance of some irreplaceable thing. Whenever the disappeared is not replaceable, and as long as it has no replacement, it is a loss. The singular is the irreplaceable par excellence: it is that which is distinct from anything similar to it and from anything that aspires or pretends to replace it. The singular cannot be expressed in terms of what appeared when it disappeared; its disappearance is a loss. But this does not apply only to the disappearance of the singular. [...] Loss is a disappearance that is 'for someone,' not only in its occurrence, but also in the way it is present in someone's World as irreplaceable (at least for the time being)” (89). Quiero agradecer al profesor Antonio Vázquez-Arroyo, del departamento de Ciencias Políticas de la Universidad de Minnesota, por su recomendación de este texto para la lectura de Lalo.

Revista Iberoamericana, Vol. LXXX, Núm. 247, Abril-Junio 2014, $653-675$
ISSN 0034-9631 (Impreso) 
otro lado, consciente de los discursos de la fotografía y la visión, utiliza su espacio conceptual como elemento estructurante para elaborar una teoría de los países invisibles. La invisibilidad de Los países invisibles (2008), de hecho, se gestiona en ese discurso que se genera entre la imagen fotográfica y el texto verbal. Miremos sólo uno de sus comentarios sobre este tema:

Tanto el exceso, como la falta de mirada y discurso, crean la condición invisible. (Dos invisibilidades: la del exceso de imágenes y la de su ausencia. En ambos casos estamos ante problemas de óptica, es decir, ante problemas teóricos que establecen las fronteras de la realidad.)

El mundo avanza hacia la exclusión del acto de mirar. El que mira con entrega (el fotógrafo, por ejemplo) se da cuenta de que progresivamente se van perdiendo los grises y los ojos se cierran. Al final quedarán como polos, extremos en un registro predeterminado, Venecia y Ruanda, la presuntuosa belleza y el vacuo horror, y estas imágenes sin dinámica, que se resumen en un eterno presente digital, constituirán lo invisible. (20)

Presuntuosa belleza, vacuo horror, son ambas el resultado del agotamiento y la invisibilidad de una particular puesta en escena y circulación de la imagen fotográfica, de su capacidad para ser, a un mismo tiempo, testimonio legible de la historia y bloque de visibilidad poética pura. Resultado que, en este siglo, genera la confluencia de la invisibilidad de países antes visibles (que puede encontrarse definida en la crítica de la puesta en circulación de la imagen desde mediados del siglo pasado hasta el presente) con la invisibilidad de países como Puerto Rico. "Velar” esa invisibilidad es la propuesta escritural de Lalo.

Lalo escribe con fotografías, es decir, escribe con sus propias construcciones fotográficas en lugar de trabajar con fotografías producidas por otros (sea éste un trabajo de diálogo, comentario, o manipulación). ${ }^{7}$ Las fotos forman parte entonces de un proceso

\footnotetext{
En la entrevista que le hice a Eduardo Lalo en julio de 2010, subrayó esta diferencia de las otras producciones híbridas de las que hablamos. Esta diferencia no se presenta aquí como una minusvalía de los otros textos, sino una diferencia en el proyecto de escritura, y en el significado mismo de la escritura y la relación entre la fotografía y el texto. La producción fotográfica, desde la selección de las cámaras, a la toma de fotos, a su escritura con el texto, fue realizada por el autor. De las cámaras fotográficas nos dice el mismo Lalo: "Los pies de San Juan fue hecho con una cámara digital Olympus (he olvidado el modelo) con una resolución que hoy parece ridícula (2.1 MP). Lo hice así porque lo que quería era tener fotos que parecieran antiguas, que estuvieran muy quemadas como en los primeros esfuerzos de la fotografía y que fueran en sepia. No tenía entonces los elementos técnicos para realizar esto en un laboratorio. donde y El deseo del lápiz significaron un regreso al negativo. Compré 2 cámaras que quiero mucho. Una Nikon F 2 y una Contax G 2. Ambas fueron adquiridas usadas y la primera podría tener por lo menos 25 años aunque estaba en excelente estado. Esta fue la última Nikon profesional completamente mecánica y es una
}

Revista Iberoamericana, Vol. LXXX, Núm. 247, Abril-Junio 2014, $653-675$
ISSN 0034-9631 (Impreso) 
escritural, se piensan como elementos de un discurso que incluye a un mismo tiempo imagen visual y texto verbal. Su producción híbrida, en particular donde y El deseo del lápiz, refleja la actualización de los discursos de fotografía y texto, específicamente como podemos observar en la teoría de Rancière: los registros de lo visible y lo decible no pertenecen indistintamente a la fotografía y a la palabra, las oraciones-imágenes que propone, es decir, las funciones de conexión y de ruptura que conforman sus instalaciones foto-verbales, no suponen al lenguaje verbal como conexión y narración y a la fotografía, o la imagen visual, como ruptura. De hecho, podría decirse que Lalo fuerza a conciencia un acto contrario: es el texto, son las citas, es la saturación misma del discurso, la que se visualiza en toda su fragmentación, lo que se manipula, con lo que se dialoga. Ese acto se indica en el texto como la única posibilidad disponible para el discurso de quien no tiene discursos. En tercer lugar, esa escritura foto-textual de Lalo puede leerse como el medio necesario para "hacer visible", para representar la invisibilidad producto de esa pérdida original y originaria.

Extraigo de los textos de Lalo una serie limitada de fragmentos verbales, de signos, de la vertiginosa presencia de signos en su literatura fragmentada y saturada al máximo con alusiones a los discursos de Occidente. Selecciono estos signos en particular porque funcionan a un tiempo como ruptura o quiebre del sentido y como puntos de visibilidad reiterada de aquello que permanece indecible pero cuyos restos se manifiestan como presencia actual en el lenguaje verbal y en la fotografía. Es decir, los discursos de Occidente han llevado a la saturación, y esta saturación y su acompañante densidad se han visto reflejadas en la literatura latinoamericana de fines de siglo (en especial en las producciones híbridas). La literatura de Lalo no es ajena a esta saturación de la literatura latinoamericana. De hecho, podríamos decir que la lleva, a consciencia, a su límite, para producir quiebres específicos en el entramado verbal. En las parataxis fototextuales, siguiendo la teoría de Rancière, el ritmo, en apariencia fragmentado, produce naturalmente operaciones de conexión y de ruptura, realizadas indistintamente por la imagen visual y por el lenguaje verbal. El ritmo de la parataxis en Lalo utiliza los signos verbales como ruptura, como puntos de fuga y quiebre para mostrar precisamente la visión de una pérdida. Las fotografías son allí entonces la narración desde ese quiebre, la visión que ha sido forzada a través de la ruptura.

cámara de 35mm grande y pesada. Todas sus graduaciones son manuales. Estas circunstancias motivaron la compra de la Contax que es una cámara mucho más pequeña (una rangefinder) que me era útil para la toma de fotos en la calle con rapidez (esta cámara enfoca y determina la velocidad automáticamente). Por esos años recorrí muchos kilómetros con las dos cámaras en mi mochila” (Correo electrónico de 19 de agosto de 2010).

ISSN 0034-9631 (Impreso) 


\section{LA ESCRITURA RAYADA}

Selecciono "la escritura rayada", título de una delas secciones de donde, como primer signo, porque a pesar de aparecer tardíamente en este texto, se produce estratégicamente como la visualización del evento de una pérdida original fundadora. Escritura rayada o acto de rayar, rayadura, que no debe leerse como se lee la tachadura derrideana. ${ }^{8}$ Lalo traza la historia de la escritura en el Caribe como el efecto de esa rayadura; la primera palabra taína que Colón consigna en su diario, la palabra canoa, debe escribirse eanoa, y la escritura en el Caribe hasta nuestros días es el reflejo de esa rayadura:

Es terrible el sarcasmo de este dato que fundaría el relato de nuestra claustrofobia cultural. El insularismo de la historia colonial que llega hasta nuestros días, nace con un concepto viajero, con el instrumento que transportaba la cultura. Esto equivalía a nombrar la muerte con el nacimiento. [...] La primera palabra escrita, lo que Colón escribió con tinta en su bitácora, no fue “canoa” sino eanoa. Desde entonces, la escritura del Caribe no ha hecho sino repetir las consecuencias de esta unión de la muerte y el nacimiento, del descubrimiento de un mundo y su condenación al silencio. [...] Durante más de cinco siglos, las letras nos han hecho pensar que esta muerte era un hecho civilizador, que la muerte fue una ganancia. Cinco siglos están determinados por una sola palabra: conquista. A este concepto se reduce la nota al calce que somos para Occidente: fueron conquistados, su exterminio fue su momento culminante de la historia y tienen desde entonces la palabra de otro. (128-129, énfasis mío)

La rayadura marca su pérdida desde un acto de violencia, desde una presencia (otra que la pérdida, pero no su sustituto: de hecho, este acto visual debe leerse junto a la palabra “consecuencia”, que subrayo en el pasaje citado). El acto visual es la representación del

8 Me parece interesante que Duchesne, en su artículo "Desde donde alguien para leer a Eduardo Lalo", dé preferencia al término "tachadura" en lugar de la frase con su adjetivo "escritura rayada" o "rayar" como verbo, al que Lalo da preferencia en su texto, como término acuñado por él, para hablar del evento de colonización como un acto de violencia. Duchesne habla de "tachar", en lugar del acto de rayar, y el adjetivo rayado, para hablar del mismo acto de violencia. Esta sustitución lleva al riesgo de acercarnos hacia la tachadura heideggeriana, que luego retoma Derrida. Y, por supuesto, creo que hay relaciones entre ambas, que en ambas se encuentra la incapacidad de nombrar nombrando, la visualización de la imposibilidad de tener acceso al ente en cuanto ente, que acompaña también a la pérdida de oralidad (sólo puede "verse", descifrarse, no puede decirse, no tiene oralidad, sonido). Pero la escritura rayada es el acto de violencia, el evento de violencia como acto, la visibilidad de la violencia. Es importante entonces asegurar, sin desestimar para nada la similitud, la diferencia entre uno y otro, escribiendo quizá un nuevo término, "rayadura”. Será entonces éste el término que utilizaré en el trabajo. Por otro lado, la tachadura de Heidegger, luego retomada por Derrida, puede verse como influencia en Lalo, pero en otro término, "marca” que utiliza en su última publicación (El deseo del lápiz, 2010). La marca como rayadura última, como la visualidad en el límite que puede llegar a producir una oralidad.

Revista Iberoamericana, Vol. LXXX, Núm. 247, Abril-Junio 2014,
ISSN 0034-9631 (Impreso) 
evento de pérdida que lleva a una serie de "consecuencias”. La primera de ellas es la incógnita de una imposible recuperación; no sólo es imposible saber cuál habría sido el curso de los eventos sin este evento inicial, sino que no hay participación posible en el sistema de daños y perjuicios, de pérdidas y restituciones, que caracterizan la historia y la economía de Occidente. Es imposible restituir lo que queda rayado, imposible volver a ponerlo en el tiempo. Lalo presenta la pérdida a través de la ruptura visual del discurso del otro, del que efectuó el acto que produjo la pérdida, aunque este acto quedara representado, por el otro y mediante el discurso del otro, como una ganancia. Desde ese momento, la escritura del Caribe ${ }^{9}$ puede leerse como una serie de acumulaciones sin ganancia, es decir; desde el punto de vista de la rayadura, la serie de acumulaciones no devengan una restitución de la pérdida, la historia se detiene para pasar a ser la historia que el otro escribe sobre esta pérdida. La rayadura es la ruptura inicial con la palabra que hace visible la invisibilidad: "Y la invisibilidad no es exclusivamente una función ocular o relativa a otros sentidos (lo que se escucha, lo que se siente ...) sino que es un lugar en la historia, la posición que se ocupa en una estructura ante los discursos de dominio y éstos, aunque tienen obvias manifestaciones económicas, tecnológicas, militares, etc. son primero que todo formas que adquiere la escritura” (Los países invisibles 27). Es ésta una referencia directa a la cita de Manuel de Diéguez que aparece en donde: Europa debe comenzar "a comprender que su destino es un destino del pensamiento" (171). Y, dentro de ese destino del pensamiento, es decir, desde los discursos de Occidente que determinan la historia, su lectura, sus archivos, la invisibilidad de Puerto Rico puede marcarse como tal, hacerse visible, a través de la rayadura.

DONDE

Es desde la rayadura que se puede volver ahora al signo más visible de la producción foto-textual de Lalo: el "donde”. Adverbio relativo, que expresa una relación de lugar, "donde” no es un espacio físico, sino una relación de espacio cargada de temporalidad. Por definición, esta relación sirve de gozne, de articulación de un espacio-tiempo relativo, que se desliza constantemente. Éste no es precisamente el caso en la escritura de Lalo:

Pensar el donde, volverlo imagen, es comprobar que el donde no es solamente un lugar. Puede estar en cualquier parte, en cualquier otro donde; porque el donde no es un lugar

9 Lalo nombra esa pérdida desde todo el Caribe, a pesar de que trabaja específicamente con el lugar que ocupa Puerto Rico dentro de los discursos de Occidente. Este gesto es importante: si es obvio que Puerto Rico nunca llegó a alcanzar su lugar en el espacio de las naciones independientes, su lectura de la historia del Caribe, de la pérdida originaria, produce una historia común que coloca la independencia de las islas del Caribe también bajo una rayadura. Observar hasta qué punto esta visión puede ser compartida con las otras naciones latinoamericanas no es la labor de este trabajo pero es una pregunta que se debe trabajar también.

Revista Iberoamericana, Vol. LXXX, Núm. 247, Abril-Junio 2014, 653-675
ISSN 0034-9631 (Impreso) 
sino un determinante de origen y estructura de límites. Y los orígenes y las fronteras son veladuras y éstas esconden y afirman el acto que esconde.

Donde de la historia, donde de lo visible y lo invisible, frontera, borde, material articulado de lo imposible de decir. (25, énfasis mío)

Es desde la rayadura que se entiende ese determinante de origen: el origen en este caso es el evento de la pérdida fundacional, que nunca se restituye, ni siquiera parcialmente, en otro evento de independencia, como ocurriera en el resto de Latinoamérica. Desde esa rayadura, el "donde” se vuelve visible donde la lengua ha quedado "incapacitada" (84). La "estructura de límites” no es tan sólo la condición insular de la isla, aunque la nombre, tanto en la palabra como en la imagen fotográfica, sino la estructura conceptual de una acumulación histórica (léase, de discursos), de una inmovilidad que hace que la historia sea imposible. "Todo listado es melancólico porque la sucesión no crea ganancias. A pesar de los simulacros, todo permanece en el mismo sitio. El donde es una burbuja que no viaja. La historia es imposible" (61). Al mismo tiempo, sin embargo, es necesario ver, leer, la forma en que se maneja el carácter visual de esta imagen como si se tratara de una directriz: la veladura (en fotografía, velar es arrojar luz, de tal manera que se arriesga una sobreexposición de la imagen), la visión que produce el signo, más allá de su quiebre, no se pretende como un signo fijo. El quiebre que produce el “donde" no es el quiebre de un espacio específico, sino el quiebre de la visibilidad de una postura conceptual. "El donde de todos y el donde de nadie. El donde que reúne fuerzas, especialmente las que no controlamos, las ciegas. El donde que ignora los gentilicios y determina las nacionalidades. El donde que nace cuando se prescinde del significado de las palabras que nos han dado" (95). Este quiebre, entonces, se pretende a un mismo tiempo como un índice específico, que refiere, en este caso, a la isla de Puerto Rico, a su iniciación histórica y sus consecuencias, pero que, debido al determinado momento histórico, será el espacio conceptual de convergencia con otros espacios, tanto latinoamericanos como a nivel mundial.

El "donde" no debe relacionarse estrechamente con el término "no-lugar" (lugar físico, real) acuñado por Marc Augé para hablar de los lugares de "pasaje transitorio"; 10 si en el caso de Augé los no-lugares son el vaciamiento de la historia producida por la supermodernidad, el donde hace del origen histórico su provocación. La variable histórica y conceptual diferencia el "donde” de esos espacios, a los que Lalo nombra lugares "indonde”: aeropuertos, cárceles, hospitales, centros comerciales, espacios producto de

10 "If a place can be defined as relational, historical and concerned with identity, then a space which cannot be defined as relational, or historical, or concerned with identity will be a non-place. The hypothesis advanced here is that supermodernity produces non-places, meaning spaces which are not themselves anthropological places and which, unlike Baudelairean modernity, do not integrate the earlier places, instead these are listed, classified, promoted to the status of "places of memory', and assigned to a circumscribed and specific position.” (Augé 77-78).

$\begin{array}{llllll}\text { Revista Iberoamericana, Vol. LXXX, Núm. 247, Abril-Junio 2014, 653-675 } & \text { ISSN 2154-4794 (Electrónico) }\end{array}$ 
un discurso específico del estado y la globalización (24). ${ }^{11}$ Ciertamente, esos "indonde", esos no-lugares que menciona por su nombre en El deseo del lápiz (2010) producen también espacios relacionados, habitados en el "donde": el caso que presenta Lalo es las "tribales asociaciones de residentes"(33). Pero al hablar del "donde”, el origen es una de las marcas principales de su existencia. Esto no significa que el "donde" sea únicamente puertorriqueño, o caribeño, sino todo lo contrario. El "donde” es un lugar conceptual compartido, que muestra su similitud de invisibilidad con otros países (Lalo menciona específicamente el Cairo en donde y Valencia en El deseo del lápiz). Se trata entonces de un espacio conceptual (y no de un lugar) que recibe la influencia de los no-lugares y que anuncia los lugares y espacios del futuro. El "donde" de Lalo, que habla específicamente de Puerto Rico y el Caribe, que se instala en esa especificidad histórica, es el anuncio del porvenir de los espacios (conceptuales) y los no lugares (físicos), del resto de la orbe.

Fragmentos. Restos. Rastros. Grieta.

La grieta remeda la escritura en su expresión mínima, en el extremo de lo esencial. Es la marca autónoma, producida por la propia energía de los materiales culturales; su presencia se da a pesar de lo construido: cemento, pavimentación, piedra, madera. Lagrietanace por la acción incontenible de micro-capas teutónicas. Es la escritura de lo humano devenido cosa, en un primer momento, antes de la acción de la mirada, es la expresión de atguien. Surge como una escritura inevitable, creada más allá de las manos. Nada, ni los materiales más sólidos, puede silenciar la grieta y, a la vez, ésta es el testimonio mismo del silencio.

[...]

La grieta es una inaudita arqueología de superficie: lo más remoto, lo acallado, lo destruido, lo extinto, aparece ante la mirada como signo hermético contemporáneo.

Eduardo Lalo, donde

${ }^{11}$ Conviene aquí citar el pasaje completo: "Los aeropuertos son la frontera del donde y a la vez el lugar que pierde progresivamente las particularidades geográficas e históricas de éste. Lugar del no-lugar. Donde indonde. El anuncio de las ciudades del futuro y la muestra de cómo las ciudades de hoy se descivilizan. Sitio intermedio y brumoso, similar en su concepción espacial a las cárceles y los hospitales en los que las libertades quedan veladas, en paréntesis, entre comillas. Lugar policíaco. Sitio perteneciente a otro mayúsculo. Intensificación del presente de urbanizaciones con barreras, vallas y guardia privada; tribales asociaciones de residentes, universo de ciudadanos desciudadanos. Ensayo general para la hipercolonización de las ciudades por los poderes del estado y del dinero, espacio para que nos vayamos acostumbrando a lo que nos espera” (24-25).

Sevista Iberoamericana, Vol. LXxx, Núm. 247, Abril-Junio 2014, 653-675 ISSN 0034-9631 (Impreso) ISSN 2154-4794 (Electrónico) 
En la vertiginosa presentación de signos que se produce a lo largo de donde, la grieta no surge como símbolo textual, nuevamente, hasta casi finalizado el texto. Sí, desde un principio, como establece el crítico Francisco Javier Avilés, Lalo demuestra su afinidad con el escritor-arqueólogo de Walter Benjamin en "Berlin Chronicle". ${ }^{12} \mathrm{Y}$, de hecho, no tan sólo en donde, sino también en Los pies de San Juan y El deseo del lápiz: castigo, urbanismo, escritura abundan las alusiones a los restos, los rastros, los fragmentos y la función de un escritor y un lector como arqueólogos (el escritor que marca el encuentro de un hallazgo y el lector que descifra la marca). La grieta, por supuesto, es en principio la falla que anuncia la destrucción, que interrumpe la historia, como nos dice Duchesne Winter al hablar de las afinidades del concepto de grieta de Lalo con el concepto de interrupción de Walter Benjamin. Para Lalo, debe leerse desde su aspecto físico real, aunque luego pase a convertirse en un concepto. Uno de los textos paradigmáticos de la utilización de este símbolo físico como anuncio de una catástrofe futura podría ser "La caída de la casa Usher”, de Edgard Allan Poe. Allí, “Quizá el ojo de un observador minucioso hubiera podido descubrir una fisura perceptible que, extendiéndose desde el tejado del edificio, en el frente, se abría camino pared abajo, en zig-zag, hasta perderse en las sombrías aguas del estanque” (Poe 234). En ese relato de Poe, la mansión, edificio arquitectónico, y simbólicamente edificio histórico-social, psicológico y lingüístico, es consciente en su superficie de los fragmentos individuales que sin embargo mantienen una "adaptación perfecta de su partes”. La superficie señala en su grieta el principio de su propia destrucción. Al final del relato, el "profundo y corrompido estanque se cerró sombrío, silencioso, sobre los restos de la Casa Usher" (247). La grieta deviene allí el señalamiento de la temporalidad de un lenguaje que, como nos dice Paul de Man, está abierto desde siempre a un movimiento de desintegración, de fragmentación. ${ }^{13}$ Inadvertidamente, o quizá no, el texto de Poe puede leerse como el anuncio de la disolución y destrucción de las posibilidades del lenguaje que marcan gran parte de la literatura, la historia y la filosofía de finales del siglo veinte y principio del veintiuno, leída desde los discursos mismos de Occidente.

Digamos, entonces, que los discursos de Occidente son conscientes de esta grieta que comienza a extenderse en toda la verticalidad de su discurso (es decir, desde todos sus tiempos y todos sus espacios). Nos lo dice el mismo Lalo: "La grieta no es nueva. Occidente también es víctima de Occidente. Tras él, que nadie se engañe, quedan también las grietas de sus vencidos” (211). Pensemos, entonces, que las fotografías que abren

${ }^{12}$ La relación de la grieta con Walter Benjamin está también trabajada en el artículo de Duchesne Winter, "Desde donde alguien para leer a Eduardo Lalo”. No repetiré en mi trabajo las propuestas de Duchesne Winter, que, por otro lado, me parecen completamente acertadas.

${ }^{13}$ Estas notas provienen de mi artículo no publicado, "La traducción como resto. Cortázar, Poe y Baudelaire”, presentado en el Congreso Transatlántico de Brown en abril 2010.

Revista Iberoamericana, Vol. LXXX, Núm. 247, Abril-Junio 2014, 653-675
ISSN 2154-4794 (Electrónico) 
el foto-texto donde, desde su misma portada (la foto indeterminada del mar que rodea todo el foto-texto) son la grieta misma de los discursos de Occidente hechos imagen para enmarcar la escritura: el edificio multipiso en proceso de convertirse en ruinas, la pared marcada y el suelo agrietado, la habitación deshecha, el cementerio que pierde el nombre propio, la espera a que cambie una señal de tráfico que no es visible porque la hipercolonización de signos ha llevado sólo a una espera sin significados, la imagen claustrofóbica de un puerto tras las rejas, todas estas fotos son precisamente la narración de los discursos de Occidente que ya hacen demasiado visible sus "grietas". Estas fotografías, como vimos al principio de este texto, son elocuentes, contienen inscritas en ellas varios relatos, son y narran las grietas de Occidente y sus discursos, desde el origen específico de la historia del caribe. La grieta verbal de Lalo, observa entonces, y hace visible, estos mismos discursos desde el espacio de la pérdida, es decir, desde el testimonio del que ha perdido y que puede, al alcanzar la visibilidad, convertirse en sujeto que existe en virtud de la declaración de la pérdida. ${ }^{14}$ Espacio precario además de mínimo, ya que la pérdida, como nos explica Adi Ophir en The Origin of Evils, enunciada por el sujeto, hecha lengua, hace surgir al sujeto pero es también la misma que lo convierte, dentro de la economía de "daños y prejuicios", en objeto de un acto de violencia, es decir, lo coloca de lleno en los discursos de otro, de donde precisamente surgió. "La grieta no permite explicar, porque le es imposible someterse a cualquier lógica. Sin embargo, tiene la fuerza de un documento, es el florecimiento de un fósil inmediato" (donde 209). Forzar la palabra a ser marca visible, en el sentido en que Lalo elaborará su teoría de la marca en su obra El deseo del lápiz, forzar la fotografía a narrar desde esa marca, es entonces el riesgo de llegar a la enunciación que se juega en la escritura foto-textual de Eduardo Lalo.

III. LA FOTOGRAFÍA: CUERPO DE LA ESCRITURA, CUERPO DE LA NARRACIÓN

Inquietar el ver quizá sea la tarea más importante del arte de nuestros días. Frente a la hipertrofia de la visión, ese inquietar hace despertar un ver sumido en un sueño profundo: el sueño del espectáculo.

Eduardo Lalo, Los países invisibles

Proponerme un pensamiento (y también una literatura) desinstitucionalizados, que estén más allá de cualquier

\footnotetext{
14 "Pero esto es imposible. No puedo irme de mí mismo, de las palabras ni de Occidente. Entre los hallazgos de la historia y las ciencias sociales y esta desmesura, está en algún lugar la grieta, la posibilidad de la pertinencia de nuestro pensamiento. Se trata de descubrir un sujeto, o acaso de inventar una temporalidad mínima, un momento, unos segundos, para que éste vehicule la palabra de alguien. Su estrechez, su mínima existencia no lo hace menos real” (donde 198).
}

Revista Iberoamericana, Vol. LXXX, Núm. 247, Abril-Junio 2014, 653-675
ISSN 0034-9631 (Impreso) 
tradición nacional, de cualquier lengua-aun de la que empleo para escribir- de cualquier género literario y sexual, que prescindiera incluso del imperio avasallante del hecho lingüístico de lo literario (por ejemplo, aquí la fotografía, pero hubiera podido ser dibujo o sonido). Recuperar así, sin haber renunciado a la página, el espacio de la oralidad. Una oralidad que sólo ocurriría en la mente, como performance de ella misma. Crear así un texto que estuviera fuera de toda oficialidad y normalidad, al que sea imposible imponerle categorías, incolonizable

Eduardo Lalo, El deseo del lápiz

La secuencia de fotos que aparece en donde más allá de su primer marco puede verse, leerse, desde una potencialidad sin habla, como el momento de un decir de un sujeto que entiende el riesgo de ese decir, y que toma el riesgo como una manera de inquietar la mirada. Hablamos desde el principio de este trabajo de una inversión estructural, donde la palabra, ciertas palabras, funcionan como imágenes en el sentido que le da Rancière al término: imagen como poder activo de la interrupción del sentido. Las fotos en donde, por el contrario, producen una secuencialidad temporal o narratividad fraseológica específicas: ${ }^{15}$ su propósito es hablar de una continuidad que parte de y es producto mismo de la ruptura producida por la historia.

¿Qué significa ese decir en términos fotográficos? ¿Cómo y de qué manera, si ya hemos visto la palabra como interrupción, podemos leer la fotografía en donde como oración o secuencia? ¿Qué propuesta histórico-discursiva propone esa construcción, consciente siempre del riesgo del decir? ${ }^{16}$ Utilizo las mismas palabras de Lalo para comenzar a explicar el significado narrativo de sus fotos:

En cualquiera de sus partes están todos los componentes del tiempo. Es por esto por lo que las cronologías son un manierismo, una forma de la ornamentación. En cualquier punto de una sucesión de eventos se halla la explicación de su resultado último; cualquier etapa, por ende, puede servir para ilustrar por entero un proceso. (La isla silente 22)

${ }^{15}$ No debe de confundirse con el concepto de fotografía secuencial, donde se incorpora una serie secuencial de momentos en una sola fotografía.

${ }^{16}$ La propuesta fotográfica de cada uno de los textos híbridos de Lalo es distinta. En Los pies de San Juan, como respuesta a la reproducción de "los usos y costumbres de nuestros ocultadores" (44), Lalo sugiere una iniciativa arqueológica: se trata allí de fragmentos con los cuales el lector irá componiendo un texto, reconstruyendo una historia, para darle a la ciudad su literatura. En El deseo del lápiz, se fotografía la marca visual en el extremo mismo de la prisión y la ruptura del habla. En estos dos textos, "la voz" queda imaginada, no dicha, desde esas marcas visuales que fotografía Lalo. En donde, por otro lado, las fotografías son un "decir" histórico desde la grieta.

Sevista Iberoamericana, Vol. LXXX, Núm. 247, Abril-Junio 2014, 653-675 ISSN 0034-9631 (Impreso) $\quad$ ISSN 2154-4794 (Electrónico) 
En la cita anterior, Lalo habla específicamente de la memoria. Pero esas mismas palabras podrían utilizarse para las fotografías de donde, y no porque la fotografía, como medio, pueda o deba leerse siempre así. Recordemos que la secuencia fotográfica en donde parte de la ruptura producida por la grieta, por la rayadura, y que habita en ese "donde” en el cual ha cesado el devenir histórico mientras continúa una sucesión temporal marcada por una pérdida progresiva. Cese producido por una serie de primeros eventos históricos que han llevado a una progresión de no eventos: Puerto Rico llega al presente sin autoridad histórica pero atiborrado, incapacitado casi podríamos decir, por los signos de la modernización y la globalización. ${ }^{17}$ En el caso específico de estas fotografías el evento histórico rememorable, o los sujetos históricos y su memoria, no son el objetivo de la representación; las fotos narran el movimiento del fotógrafo en un presente marcado a un mismo tiempo por los signos de la modernidad y las marcas de un proceso de pérdida y ruina.

¿Cómo definir el cese de la historia y la simultánea continuidad temporal en la fotografía? El deslizamiento adverbial seleccionado por Lalo es aquí clave crucial: el tiempo y el espacio buscan desnudarse de sus códigos históricos. Fracturar la historia fotográficamente, en este caso, es negar los códigos usuales por los cuales y con los cuales el discurso fotográfico "hace historia": "descolonizar" la foto. Las técnicas fotográficas que lo logran en un primer nivel son sencillas. Hay una preferencia por el sangrado completo (donde el objetivo se acerca a la imagen y hace desaparecer sus contornos, sus "marcos" de lectura, dando prevalencia a la imagen misma sobre su marco y enfatizando la imposibilidad de una mirada totalizadora o contextualizadora, la mirada que pretende, precisamente, el discurso histórico). Este acercamiento del objetivo al objeto hace desaparecer también la línea del horizonte utilizada como línea contextual, haciendo desaparecer también la relación entre los espacios y las cosas que es una clave fundamental para la lectura codificada. Al poner énfasis en el primer plano de los objetos y los sujetos, se logra dar mayor materialidad y corporeidad al objeto o al sujeto fotografiado, aunque éstos no queden definidos "históricamente". Es decir, los sujetos fotografiados, sean establecimientos, personas, perros, señales de tráfico, paredes, calles entran en la equivalencia de esa cercanía a la cámara. Se elimina por completo la fotografía de monumentos, base de la simbolización histórica y del discurso turístico colonial (la notable excepción es la fotografía del capitolio, elaborada a manera de caricatura, de la página 52, o el hombre y la garita de la página 183). Se elimina a los sujetos identificables o personajes, dando preferencia a individuos no identificables.

${ }^{17}$ Y, de hecho, ¿hasta qué punto podría leerse la situación actual de la Universidad de Puerto Rico en el recinto de Río Piedras como el producto de una serie de no eventos unidos a la globalización y "modernidad" sin sentido, que han llevado a la suspensión de la sección de humanidades del recinto, el centro del saber intelectual puertorriqueño?

ISSN 0034-9631 (Impreso) 
Aquí surgen dos excepciones notables. En primer lugar, la foto de Adónica y Diego (hijo de Lalo) de la página 82, que marca, no tanto la presencia de los sujetos fotografiados como del fotógrafo, presencia que se repite en los autorretratos de las páginas 102, 103 y 226. En segundo lugar tenemos al sujeto histórico (el ex-gobernador Roselló) presente como tatuaje en la cintura de una mujer retratada de espalda, en la foto de la página 46; aquí el tatuaje se convierte en signo altamente simbólico, una cicatriz sobre el cuerpo sin identidad, cicatriz que, como Lalo mismo dice más tarde en el texto, nos hace por primera vez inteligibles. ${ }^{18}$ Se utiliza por completo la fotografía en blanco y negro (y esto con un propósito que Lalo mismo define en Los pies de San Juan: eliminar la "banalidad”, llegar a un significado “que está más allá del color”). ${ }^{19}$ Se suprimen la mayoría de los aparatos simbólicos históricos para dar preferencia a los signos globales de la modernidad, pero sin referentes geopolíticos precisos (semáforos y otras señales de tráfico, nombres de calles, a veces identificables para alguien que conozca bien a Puerto Rico, carteles de establecimientos comerciales abandonados...). Los títulos de las fotos (colocados no como leyendas textuales junto a las fotos, sino al final, como claves prescindibles de sentido), si bien señalan ese donde puertorriqueño, subrayan al mismo tiempo un principio de no determinación: la palabra no identifica, no codifica, no historiza, más allá de lo que podría hacerlo la fotografía misma. Y sin embargo, a pesar de la intencionada eliminación de los marcos de codificación e historización fotográfica, la narración que plantean no es la representación de un no lugar desprovisto de una antropología, sino todo lo contrario: se trata de una narración que sólo tiene sentido desde los límites específicos de la historia puertorriqueña, desde su grieta, su rayadura, señalada desde el donde fronterizo de la foto de la cubierta, la extensión del

${ }_{18}$ Esta foto es indicativa del lugar en el que se reúnen cuerpo y escritura junto con la ausencia del sujeto, cuerpo y escritura como el resultado de la escritura rayada sobre la que aborda más tarde Lalo en el texto: "Esta es, la escritura rayada, la palabra como cicatriz de una herida inexpresable; la marca unívoca dejada por el que usó y abandonó el cuerpo expoliado. La 'independencia' en el Caribe, y no sólo aquí, es un abandono; el dejar atrás un cuerpo marcado por lo que fue escrito. Y este cuerpo agoniza a lo largo de toda su existencia” (131). Tanto la fotografía del tatuaje, como el texto donde se habla del uso de "papi” para el que da origen y el que penetra, parecen ser ejemplos banales de una realidad que absolutamente deja de serlo: ésta es, de cierta manera, la secuencia de lo que no tiene término, lo que carece de evento histórico. Pero, afirma Lalo, por primera vez esas escrituras, esas “derrotas ideológicas” nos vuelven inteligibles frente al mundo: “¿Hoy escribimos desde la claudicación progresiva de las soberanías; desde una suerte de 'derrota' ideológica? La historia del mundo, acaso por primera vez, nos hace inteligibles. Somos el futuro de la región y de gran parte del orbe. Más que antes, hace sentido ser y ejercer la resistencia [...] ¿La colonia más antigua del planeta puede sorprendentemente convertirse en el experimento fatalista del futuro del mundo? (93)

19 "El color es la apariencia de la banalidad. [...] Es como decir, aquí está esto que siempre has visto y no lo has visto. Robert Frank decía que el blanco y negro era la profundidad. No sé si es tanto, pero la imagen sin color es la mirada, su congelamiento, su privilegio de ser extraída de la sucesión infinita y condenada al olvido de los instantes. [...] El significado último está más allá del lenguaje, como el significado está más allá del color” (54).

ISSN 0034-9631 (Impreso) 
mar que rodea a la isla.

La narración fotográfica podría dividirse, catalogarse. Por un lado, se trata del relato de los signos de Occidente y su relación histórica con la isla de Puerto Rico, desde las señales de tráfico (semáforos, carteles, marcadores de calles o de pueblos), hasta el espejo retrovisor donde un niño espera el futuro desde una mirada hacia el pasado (20), o el espejo roto sobre un catre que señala sin ocultamientos los ocultamientos de nuestra memoria rota $(178,179)$. Por otro lado, se trata de los signos comerciales: gomeras $(67)$, banco de sangre (67), ropa en la isla del encanto $(68,69)$, calabazas “clonadas” (104), maniquíes (140-141); todos ellos podrían resumirse en la imagen fotográfica de los números de la lotería en la pared (166). Las marcas en la pared, los grafitos, aparecen como rayaduras, escrituras desde un muro agrietado (118). Sale entonces de la piedra la rayadura de la escritura, sale como marca de una oralidad posible sobre la piedra, sale la rayadura fantasma para hacer brotar los fantasmas de la historia (40, 41), para marcar el día triste $(64,65)$ o la confesión $(180,181)$, o el estado del limbo de la isla (50-51), todo lo cual podría resumirse en la pared pintada de Río Piedras que señala: “Escrementos y s[ilegible] cuentos” (222-223).

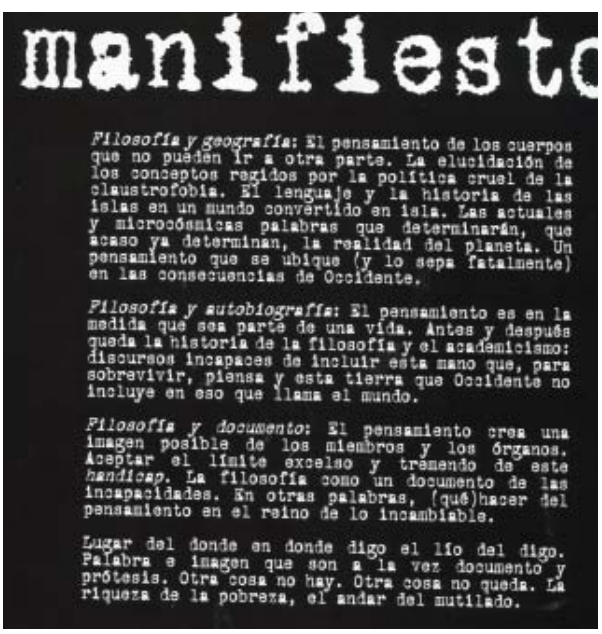

“Pequeño manifiesto” - 227

A lo largo de toda la escritura e inscrito en el "pequeño manifiesto" que concluye el texto, surge entre la foto y la palabra el cuerpo como concepto, el cuerpo como sujeto, el cuerpo como narración que se arriesga a decir. Surge como su pensamiento: "El pensamiento de los cuerpos que no pueden ir a otra parte", y que desde su claustrofobia se instalan (como lo hace la fotografía a lo largo de todo el texto) "en las consecuencias de Occidente” (227). Surge en función de un devenir vital: “El pensamiento es en la medida

Revista Iberoamericana, Vol. LXXX, Núm. 247, Abril-Junio 2014, $653-675$
ISSN 0034-9631 (Impreso) 
que sea parte de una vida”, de un yo que utiliza la fotografía para unir autobiografía y cuerpo, autobiografía y escritura foto-textual en "esta mano que, para sobrevivir, piensa”, aunque Occidente se niegue a incluirla en su discurso. Surge en su desmembramiento: "El pensamiento crea una imagen posible de los miembros y los órganos”. Surge el cuerpo de la escritura y de la fotografía como una prótesis, la prótesis que permite "el andar del mutilado”. Cuerpo incompleto, representado así específicamente en la fotografía de un cuerpo joven (90), y en el sueño de mutilación que tuvo el hijo del autor en el texto como única salvación posible. ${ }^{20}$ Escritura y fotografía de un cuerpo que busca el derecho a llegar a ser sujeto.

¿Dónde puede encontrarse el habla de ese cuerpo, de ese sujeto que, en su necesidad de escritura, busca ser alguien? ¿Dónde se encuentra su espacio de escritura, su voz? ¿Dónde su texto incolonizable?

El grito se coloca en el espacio mismo de la grieta.

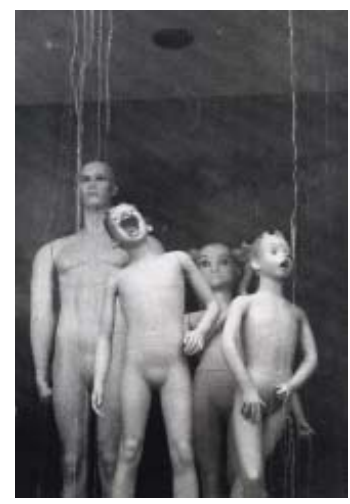

Vitrina (el grito de San Juan), 192-193 [detalle]

\footnotetext{
20 "Me entero del sueño de mi hijo mayor. Sabe que estoy muy enfermo y que la muerte me espera. Es el cinco de enero y debo morir el seis, día de la Epifanía. A las once y cincuenta y nueve de la noche, conoce que la única posibilidad de evitar mi muerte consiste en que en ese último minuto me ampute la pierna derecha. Despierta en el momento en que emprende el acto terrible de salvarme. Epifanía significa también descubrimiento, hallazgo lúcido. Mi hijo sólo me puede salvar mutilándome. Un niño, que desconoce la historia, la carga. 'Sabe' que el cuerpo que es una extensión del suyo está escrito, igual que él, por una pérdida. 'Nace’ así al conocimiento de la destrucción que nos determina. Me corta para posibilitarme vivir” (128-129).
}

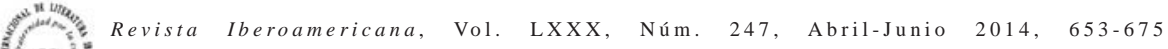
ISSN 0034-9631 (Impreso)

ISSN 2154-4794 (Electrónico) 
BiBLIOGRAFÍA

Augé, Marc. Non-Places: Introduction to an Anthropology of Supermodernity. Londres: Verso, 1995.

Avilés, Francisco Javier. "Estética del derrumbe: escritura y deambular urbano en la obra de Eduardo Lalo”, [texto no publicado aún, citado con el permiso del autor].

Cancel, Mario R. Literatura y narrativa puertorriqueña: la escritura entre siglos. Colombia: Pasadizo, 2007.

Duchesne Winter, Juan. "Desde donde alguien para leer a Eduardo Lalo”, Katakay 6 (2008): 7-16.

Lalo, Eduardo. donde. San Juan: Tal Cual, 2005.

El deseo del lápiz. Castigo, urbanismo, escritura. San Juan: Tal Cual, 2010.

La isla silente. San Juan, Santo Domingo: Isla Negra, 2002.

Los países invisibles. San Juan: Tal Cual, 2008.

Los pies de San Juan. San Juan: Tal Cual, 2002.

Mitchell, W.J.T. Cloning Terror. The War of Images, 9/11 to the Present. Chicago: U of Chicago P, 2010.

Ophir, Adi. The Order of Evils. Massachussets: MIT, 2005.

Poe, Edgar Alan. Obras en Prosa I. Cuentos. Julio Cortázar, trad. Río Piedras: La Editorial de la Universidad de Puerto Rico, 2009.

Rabaté, Jean-Michel. Writing the Image Alter roland Barthes. Filadelfia: U of Pennsylvania $\mathrm{P}, 1997$.

Rancière, Jacques. The Future of the Image. Gregory Elliot, trad. Londres: Verso, 2007.

Sánchez González, Luis. “Jean Baudrillard: Simulacro, seducción, ilusión, fotografía”. <http://espacio.postgradofilosofia.cl/wp-content/uploads/2008/05/jeanbaudrillard_-simulacro-seduccion-ilusion-fotografia.pdf>. 21 febrero 2011.

Schwartz, Marcy E. y Mary Beth Tierney-Tello, eds. Photography and Writing in Latin America: Double Exposures. Nuevo México: U of New Mexico P, 2006.

Tierney-Tello, Mary Beth. "On Making Images Speak. Writing and Photography in Three Texts from Chile”. Photography and Writing in Latin America: Double Exposures. Marcy E. Schwartz y Mary Beth Tierney-Tello, eds. Nuevo Mexico: U of New Mexico P, 2006. 87-116.

Revista Iberoamericana, Vol. LXXX, Núm. 247, Abril-Junio 2014,
ISSN 0034-9631 (Impreso) 
